\title{
O bestiário poético de Manoel de Barros em Arranjos para assobio
}

\section{The Poetic Bestiary of Manoel de Barros in Arranjos para Assobio}

\section{El bestiario poético de Manoel de Barros en Arranjos para assobio}

iD (9) Pedro Carlos Louzada Fonseca

Universidade Federal de Goiás

pfonseca@globo.com

Resumo: Este artigo examina uma das mais significativas propriedades da construção poética de Manoel de Barros em Arranjos para assobio, a ressignificação da simbologia da natureza e do seu reino animal de influência buscada na tradição do bestiário medieval. O artigo demonstra, por meio de uma análise comparativa, semelhanças entre imagens e figuralidades da poesia de Manoel de Barros e o bestiário medieval, aproximando-as em termos de visão e entendimento do Mundo: a compreensão de que a inteireza da existência está na fragmentação das coisas e nas harmonias das suas inusitadas aproximações.

Palavras-chave: Poesia e bestiário. Visão de mundo. Manoel de Barros. Arranjos para assobio.

\begin{abstract}
This article examines one of the most significant properties of Manoel de Barros's poetic construction in Arranjos para assobio, namely, the re-signification of the symbolism of nature and of its animal kingdom which is sought in the bestiary medieval tradition. The article demonstrates through a comparative analysis that exist similarities between images and figuralities of Manoel de Barros' poetry and the medieval bestiary which approach them in terms of vision and understanding of the World: the
\end{abstract}


understanding that the wholeness of existence lies in the fragmentation of things and in the harmonies of their unusual approximations.

Keywords: Poetry and bestiary. Poetic symbolism. Word vision. Manoel de Barros. Arranjos para assobio.

Resumen: Este artículo examina una de las más significativas propiedades de la construcción poética de Manoel de Barros en Arranjos para assobio, cuál sea, la resignificación de la simbología de la naturaleza y de su reino animal de influencia buscada en la tradición del bestiario medieval. El artículo demuestra, por medio de un análisis comparativo, semejanzas entre imágenes e figuras de la poesía de Manoel de Barros y el bestiario medieval acercándolas en términos devisióny entendimiento del Mundo: el entendimiento de que la entereza de la existencia está en la fragmentación de las cosas y en las armonías de sus inusuales aproximaciones.

Palabras clave: Poesía y bestiario. Visión de mundo. Manoel de Barros. Arranjos para assobio.

Submetido em 21 de maio de 2020.

Aceito em 10 de dezembro de 2020.

Publicado em 16 de julho de 2021. 


\section{Introdução}

A refletir-se sobre a existência de uma conexão de forma e sentido entre o modo de ser do bestiário, produzido originalmente na Idade Média, e os seus desdobramentos na poesia dessa época, ou mesmo dos tempos modernos e contemporâneos, a ideia básica de tal aproximação adviria do fato de o bestiário e a poesia terem em comum o propósito de cuidarem da natureza no seu sentido edificante para o homem e o mundo. Com base nessa suposição fundamental, o presente artigo examina a presença do tratamento simbólico do imaginário bestiário na poesia de Manoel de Barros vis-à-vis à própria função de a sua poesia poder trazer uma visão de mundo com base na conformação da natureza e dos seus seres animais.

Não é desnecessário lembrar que os chamados livros bestiários medievais foram uma sui generis, gênero de escrita que teve o seu ápice de florescimento na Europa dos séculos XIII e XIV. Dada a natureza simbólica e figurativa dos animais ou bestas neles descritos, os bestiários medievais constituíram uma espécie de pseudo-zoologia, no sentido de que as suas espécies eram, via de regra, descritas e comentadas nos seus aspectos simbólicos, geralmente comprometidos com intenções religiosas de ascendência bíblico-cristã e intenções doutrinárias, cujas metáforas edificantes visavam precipuamente a salvação do crente. Se, entretanto, com o passar dos tempos, esse protótipo medieval tenha perdido a sua aura moralizante, não terminaria por perder o seu forte valor simbólico agora desdobrado na significação dos animais em referência a outros temas e contextos seculares (FONSECA, 2011).

Uma das mais conceituadas definições de poesia que parece abrigar essa relação, enquanto portadora daquele sentido edificante acima referido, pode ser buscada em Octavio Paz, no seu sentido dado à poesia como uma prática vitalista, onde "o poema é um caracol onde ressoa a música do mundo, e métricas e rimas são apenas correspondências, ecos, da harmonia universal" (1982, 
O bestiário poético de Manoel de Barros em Arranjos para assobio Pedro Carlos Louzada Fonseca

p. 15). A consideração de Paz coaduna-se perfeitamente com a maneira de a visão medieval ter captado muito bem o sentido da natureza criada por Deus, que compõe um perfeito coro harmônico no qual só os desígnios secretos da onisciência divina dão a entender e justificar (FONSECA, 2011, p. 76; ARMAND, 1992, p. 830). Talvez seja nessa mesma direção de entendimento que Ana Maria Lisboa de Mello coloca a poesia como "expressão simbólica e movimento rítmico [que] associam-se para proceder a uma revelação" (2002, p. 53), que se baseia naquilo que Alfredo Bosi chama de resistência da poesia pelo seu contínuo harmonioso (1987, p. 169).

Com base nessas considerações, a escolha de Manoel de Barros para este estudo da relação entre bestiário e poesia justifica-se ainda, para além da constatação de uma presença contínua de motivos imaginários e simbólicos do mundo animal em sua poesia, pela maneira singular com que o poeta os aborda, motivando-se por um imaginário aberto a múltiplas ligações do homem com a natureza. Visto isso, este artigo examina o livro de poemas Arranjos para assobio (1982), observando, de um lado, recursos poéticos empregados característicos da poesia contemporânea, como a busca incessante da palavra poética; e de outro, a questão da influência motivacional e simbólica do bestiário na poesia do autor. Assim, a escolha desse livro de poesia justifica-se pela exemplaridade mostrada dos rumos e tratamento desse expediente poético.

\section{Breve visita à natureza e ao bestiário poético de Manoel de Barros}

Manoel de Barros (1916-2014) surge no panorama das letras nacionais em 1937, com a publicação de Poemas concebidos sem pecado, e segue até 2013 com expressiva produção poética. A sua poesia, entre outras propriedades de ímpar fazer poético e singularidade artística, busca a expressão de uma atitude de apresentação convergente do sentir e do pensar em um impartível conjugar de horizontes (PRIOSTE, 2006, p. 13), promovendo um constante 
"arejamento das palavras, inventando para elas novos relacionamentos, para que os idiomas não morram a morte por fórmulas, por lugares comuns" (BARROS, 2002, p. 47). Assim, esse tratamento constitui as matérias-primas da sua poesia, sobretudo, aquelas desgastadas, "prostituídas, decaídas" que, com prazer, Barros arruma-as "num poema, de forma que adquiram nova virgindade" (GUIZZO, 1992, p. 310). O poeta apresenta um universo nada urbano, onde animais e elementos do mundo natural compõem um verdadeiro processo simbólico e imaginário de troca de sentidos e de sinestesia (RODRIGUES, 2006, p. 19), muito próprio da criação do bestiário. Um local ancestral, onde seres miúdos e animais silvestres reinam e compõem um bestiário particular executado com uma linguagem sem restrições criativas.

É consenso considerar nas civilizações de forma geral, e na Ocidental em particular, as imagens dos animais no seu valor simbólico de forte carga poética, pois, desde a sua origem religiosa criacionista, eles foram vistos como a contraparte animada mais aproximada do humano e, portanto, digna de uma maior consideração existencial e filosófica. Esse pensamento remonta às mais antigas cosmogonias míticas e históricas do mundo antigo, passando por ressignificações ocorridas no âmbito da tradição medieval, acerca da natureza e dos seus diversos animais, até chegar às concepções modernas e contemporânea sobre o assunto (FONSECA, 2003, p. 174). Desse simbolismo animal, como de tantos outros simbolismos ligados à natureza e expressos na arte e na literatura, as suas abordagens crítico-teóricas esbarram quase sempre na proposta lacaniana que considera o valor do simbólico, principalmente na poesia e na literatura, como uma fala que se busca para além do que se pretende significar. Isso ocorre quando o significante se desloca da sua função de significado, enquanto nomeação e designação, e institui na linguagem de dimensão simbólica para além do simples imaginário. Portanto, liberto da obrigação referencial, o simbólico institui inusitadas relações de que a poesia e outras formas de expressão artística se servem para expandir a sua significação (LACAN, 1966). Manoel de Barros, como 
O bestiário poético de Manoel de Barros em Arranjos para assobio Pedro Carlos Louzada Fonseca

se verá adiante através da análise dos seus poemas escolhidos, emprega esse poder de significação simbólica para produzir o seu bestiário poético num sensível desdobramento do que originalmente se propôs o bestiário medieval.

Assim, a imagem do animal torna-se exegeticamente reinterpretada, e Manoel de Barros torna-se, entre outros poetas de sua cepa, um verdadeiro manancial cultor dessa temática poética. Em sua poesia, mostra-se sintonizado com o pensamento arcaico que expressa a religiosa e necessária convivência harmônica do homem com a natureza e os seus seres, deles aprendendo os caminhos simbólicos para a sua realização existencial. Os seres do mundo natural figuram na poesia de Manoel Barros como uma expressão da natureza humana; e o locus poeticus pantaneiro, com os seus motivos e realidades particulares, eleva-se à dimensão do universal.

A bem da verdade, essa associação poesia e natureza antecipa-se em alguns dos títulos das obras do poeta, a exemplo de o guardador de águas, Concerto a céu aberto para solos de aves; 0 fazedor de amanhecer, Cantigas para um passarinho à toa; Poemas rupestres; Compêndio para uso dos pássaros. Desse modo, o estudo do bestiário ressignificado na poesia de Manoel de Barros cumpre ainda a satisfação de uma das mais caras atitudes da visão medieval frente à natureza e os seus seres, qual seja, a admiração pelas mirabilia criadas por Deus para o ensinamento humano.

Em seus livros, Manoel de Barros poetiza a admiração e a reflexão sobre a natureza pantaneira na sua criação cosmogônica com o poema "Anúncio" do Livro de pré-coisas, dizendo ser a obra não sobre o Pantanal propriamente real, mas antes, no seu sentido anunciador e iniciático, composto por míticos enunciados contrastantes em que 
o organismo do poeta adoece a Natureza.

De repente um homem derruba folhas. Sapo nu tem voz de arauto. Algumas ruínas enfrutam. Passam louros crepúsculos por dentro dos caramujos. E há pregos primaveris.

(Atribuir natureza vegetal aos pregos para que eles brotem nas primaveras... Isso é fazer natureza.

Transfazer.)

Essas pré-coisas de poesia.

(BARROS, 2003b, p. 09)

O espaço anunciado pelo poeta compõe-se de elementos da natureza arranjados de maneira original, mostrando a possibilidade de acesso ao que acredita ser o sentido verdadeiro das coisas, e de tudo, na "transposição de uma linguagem nova para chegar a uma estética inaugural, convergindo para um conceito de Poética que leva a invenção de uma obra de arte" (VASCONCELOS, 2005, p. 261). E o sentido íntimo dessa poética inaugural completa-se na poesia de Manoel de Barros com a ideia de outridade, com a possibilidade de um consórcio entre os homens e os seres naturais.

Nessa perspectiva, a poesia de Manoel de Barros explora a outridade da natureza e dos seus seres naturais considerados em sua comunhão íntima com o humano, em que

[...] o movimento íntimo para "outrar-se", observado nos poemas arranjados por Barros, reflete o desejo de ter várias perspectivas simultâneas para perceber melhor o mundo. O constante movimento torna anacrônico o conhecimento e nos coloca na mesma situação que a dos animais, árvores, pedras, águas [...] cada qual com seu modo peculiar de interagir com mundo corpóreo, submetido ao nascimento, à transformação ou à morte conhecidas por meio das sensações (RODRIGUES, 2006, p. 65).

O percurso poético de Manoel de Barros compreende a natureza em sua totalidade, partindo de uma nova dimensão de visão, 
do enfoque microcósmico do mundo dos animais que rastejam, como as lesmas, as lagartixas e os ínfimos seres que teluricamente têm o privilégio de saber ouvir as fontes da Terra, como os do poema "Ver", de Memórias Inventadas - A Infância, em que o poeta confessa:

gostava muito, a esse tempo,

de todos os seres que andavam a esfregar as barrigas no chão. Lagartixas fossem muito principais do que as lesmas nesse ponto. Eram esses pequenos seres que viviam ao gosto do chão que me davam fascínio. Eu não via nenhum espetáculo mais edificante do que pertencer do chão. Para mim esses pequenos seres tinham o privilégio de ouvir as fontes da Terra.

(BARROS, 2006a, p. 32)

Essa mesma inclinação poética para a posse da sabedoria natural das coisas e dos seres comparece nas Escrituras, justificando a vocação religiosa do bestiário medieval, naquela passagem de Jó 12: 7-8, em que se concita a busca do verdadeiro conhecimento nas lições divinas dos animais:
Pergunte, porém, aos animais, e eles o ensinarão, ou às aves do céu, e elas lhe contarão;
fale com a terra, e ela o instruirá, deixe que os peixes do mar o informem.
Quem de todos eles ignora que a mão do Senhor fez isso? Em sua mão está a vida de cada criatura e o fôlego de toda a humanidade.

Dessa forma, tanto para os medievais quanto para Manoel de Barros, a natureza e os seus reinos estão investidos de um revelador poder divino atribuído pelo poeta à natureza em forma de fé altamente sensibilizada na escolha dos preciosos vocábulos da sua mística religiosa, quando o poeta revela: 


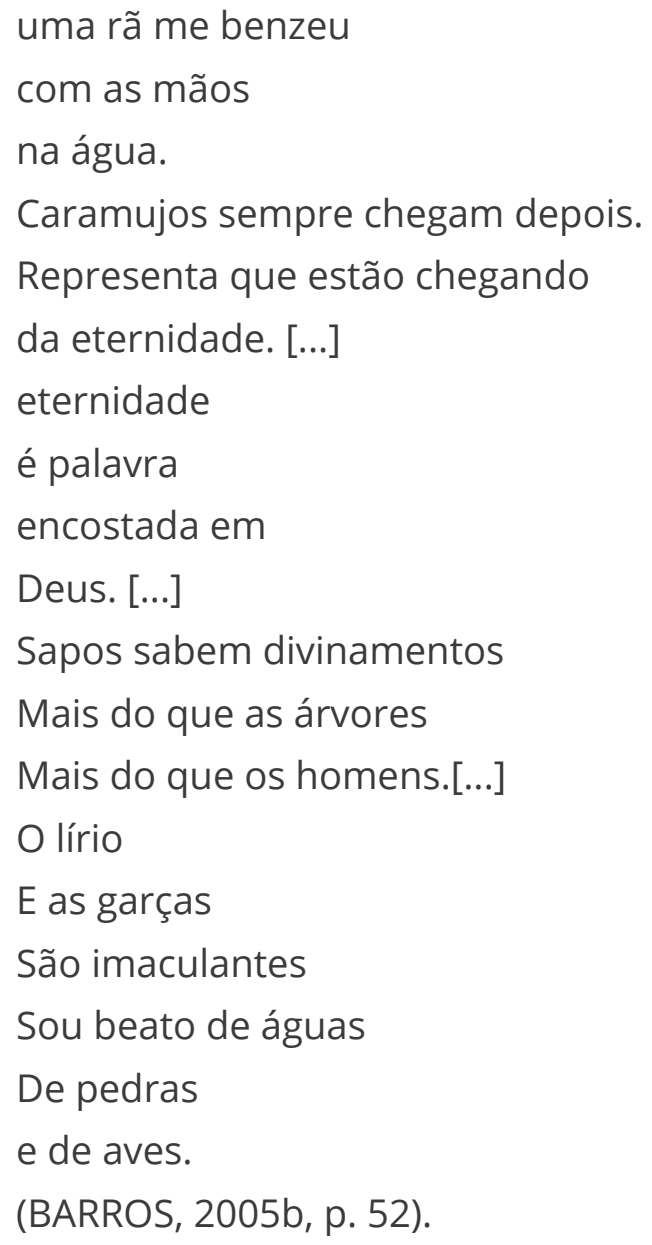

É na vida dos seres ordinários da natureza chã que Manoel de Barros busca o análogo grandioso dos glosados e desgastados cânones da tradicional sublimidade poética, reinventando-os na sua especial dedicação dirigida aos animais que pululam e rastejam na sua poesia que dá lugar de destaque a caramujos, lesmas, formigas, jacarés, cigarras e outros seres que, insignificantes aos olhos do atarefado homem racional, a partir da sua própria realidade, subvertem o mundo dito normal, quebrando-o, desligando a palavra das informações e antecedentes culturais preexistentes (MENEZES, 2001). A poesia de Manoel de Barros resgata e redimensiona o trivial e o comezinho, realizando uma verdadeira poética do prosaico com a finalidade de exibir o homem em comunhão transformadora com a natureza, utilizando-se de nexos inesperados e arranjos impertinentes, com o que mostra que entre as coi- 
O bestiário poético de Manoel de Barros em Arranjos para assobio Pedro Carlos Louzada Fonseca

sas existe uma inusitada semelhança e entendimento de sentidos (GRÁCIA-RODRIGUES, 2006, p. 1085).

Na poética de Manoel de Barros, percebida como fragmentária, o leitor depara-se com uma realidade estilhaçada e marcada pela invenção de uma nova linguagem, uma vez que desconstrói para construir. De modo que sua obra caracteriza-se como um verdadeiro artesanato da palavra ou, às vezes, como um grande laboratório vocabular em que o artista atua sobre cada significado verbal e continua em seu trabalho criativo de novas dimensões linguísticas (CAMARGO, 1997).

Até agora neste artigo foi ensaiada uma leitura horizontal das obras do autor, a fim de apreender traços da sua cosmovisão poética e apontar traços singularizadores de seu projeto literário. A seguir, o exame do seu livro de poemas Arranjos para assobio, especificamente proposto para análise e interpretação da sua recorrência temática, será feito com o objetivo de explorar os poemas que o compõem de forma vertical, no que se refere à presença de elementos formais, conteudísticos e expressivos, buscados à tradição do bestiário.

\section{O bestiário poético de Manoel de Barros em Arranjos para assobio}

O que pode ser chamado de bestiário poético pantaneiro de Manoel de Barros encontra-se muito bem representado no seu livro de poemas Arranjos para assobio, formado pelos títulos: "Sabiá com Trevas", com quinze poemas autônomos; “Glossário de transnominações em que não se explicam algumas delas (nenhumas) - ou menos", que é um glossário das palavras cisco, poesia, lesma, boca, água, poeta, inseto, sol, trapo, pedra e árvore; “Exercícios cadoveos"; "Exercícios adjetivos" e, finalmente, o capítulo que dá título ao livro "Arranjos para assobio", que se apresenta composto em formato de dicionário. Mesmo uma rápida apreciação desses títulos pode evidenciar, dada a sua natureza compósita e diversi- 
ficada, aquela atitude singularmente experimental da arte poética de Manoel de Barros.

Em "Sabiá com trevas", Manoel de Barros propõe uma comunhão perfeita com todas as coisas e seres do pantanal através do conhecimento pelos sentidos, realizando uma afinidade sensória e erótica com a natureza, em que só se conhece por meio de emanações, aderências e incrustações. Nesse universo poético, tudo é tudo, um sapo é nuvem e o poeta é a parede em que os caramujos sangram. Aquém dos limites da racionalidade e das convenções do conhecimento, para entender o que é uma lagartixa, o poeta vive a lagartixa, é a lagartixa, e a apreensão das coisas vem por intermédio do corpóreo (WALDMAN, 1992, p. 4). Em Arranjos para assobio, assim como em Matéria de poesia, Livro de pré-coisas, o guardador de águas, Concerto a céu aberto para solos de ave, o intercâmbio entre o homem e a natureza aparece na interação entre ar, água, árvore, ave, verme, peixe, réptil, casa e poesia, os quais compõem um todo indissociável neste pequeno bestiário, todos numa relação de coexistência.

No universo poético instaurado por Manoel de Barros, a apreensão fluida da natureza conferida no Pantanal é sentida em permanente trânsito pelo poeta como transmutação dos seres sem o vício alienante do pensar metafísico:

Mais que referente geográfico, em constante decomposição e renovação, o Pantanal configura-se como um mundo fluido e circular onde a vida e a morte fervilham no rastro animal e vegetal. A transmutação da morte em vida não só afasta esses grandes temas de qualquer esquadro metafísico como cria deles uma imagem em permanente trânsito (WALDMAN, 1992, p. 15).

Desse modo, na poesia de Manoel de Barros, o seres e os animais do seu bestiário poético falam muito com o corpo, com seu estado de corporeidade plena, linguagem extremamente apropriada para engravidar de densidade as palavras e os seus significados (RODRIGUES, 2006, p. 46). Assim, outros animais da sua 
O bestiário poético de Manoel de Barros em Arranjos para assobio Pedro Carlos Louzada Fonseca

poética da natureza chã comparecem magnificamente na poesia desmistificadora de Barros, onde a imagem de um pré-lógico sapo adquire dimensões cósmicas:

Borboleta morre verde em seu olho sujo de pedra.

O sapo é muito equilibrado pelas árvores.

Dorme perante polens e floresce nos detritos.

Apalpa bulbos com os seus dourados olhos.

Come ovo de orvalho. Sabe que a lua

Tem gosto de vagalume para as margaridas.

Precisa muito de sempre

Passear no chão. Aprende antro e estrelas.

(Tem dia o sapo anda estrelamente!)

Moscas são muito predominadas por ele.

Em seu couro a manhã é sanguínea.

Espera as falenas escorado em caules de pedra.

Limboso é seu entardecer.

Tem cios verdejantes em sua estagnação.

No rosto a memória de um peixe.

De lama cria raízes e engole fiapos de sol.

(BARROS, 1998, p. 27)

Primando-se singularmente por um palmear e fazer palpitar o chão, a poesia de Manoel de Barros dá vida e resgate poético ao entulho que incomoda sensibilidades ditas de bom gosto. Essa poesia do apogeu do chão vale-se de uma linguagem inovadora, e o poeta maneja a palavra de forma incomum aos hábitos dos leitores, criando um chocante universo do chão (BARBOSA, 2003). E essa realidade inusitada, extremamente poética, ocorre no seguinte poema de Arranjos para assobio, em que desfilam preferidos espécimes animais que compõem o universo do mínimo e do chão do bestiário poético do autor: 
No chão, entre raízes de inseto, esma e cisca o sabiá.

É um sabiá de terreiro.

Até junto de casa, nos podres dos baldrames, vem

apanhar grilos gordos.

No remexer do cisco adquire experiência de restolho.

Tem uma dimensão além de pássaro, ele!

Talvez um desvio de poeta na voz.

Influi na doçura de seu canto o gosto que pratica de ser uma pequena coisa infinita do chão.

Nas fendas do insignificante ele procura grãos de sol.

A essa vida em larvas lateja debaixo das árvores o

sabiá se entrega.

Aqui desabrocham corolas de jias!

Aqui apodrecem os vôos.

Sua pequena voz se umedece de ínfimos adornos.

Seu canto é o próprio sol tocado na flauta!

Serve de encosto pros corgos.

Do barranco uma rã lhe entarda os olhos.

Esse ente constrói o álacre.

É intenso o gárrulo: como quem visse a aba verde das horas.

É ínvio o ardente que o sabiá não diz.

E tem espessura de amor.

(BARROS, 1998, p. 35)

O universo poético de Manoel de Barros é composto por temas abarcantes, verdadeiros arquissemas referenciais à natureza que se traduz em "árvore, sapo, lesma, antro, musgo, boca, rã, água, pedra, caracol" (TURIBA, 1996, p. 327). O poeta está em constante simbiose com a natureza e os seus animais eleitos, sendo até mesmo possível conceber o mundo natural se hominizar e o corpo se expressar no ambiente, não como centro, mas como intersecção. Todos num mesmo patamar, em que homem e bicho se igualam em constante estado de transformação: "depois que todos se deitassem, eu iria passear sobre os telhados adormecidos. / Apenas me debatia contudo quanto a lagartixa de rabo cortado" (BAR- 
O bestiário poético de Manoel de Barros em Arranjos para assobio Pedro Carlos Louzada Fonseca

ROS, 1998, p. 21). Nas palavras de José Carlos Prioste, "este aflorar multivalente é constituinte do próprio ser que não se institui pela unidade de uma identidade da unicidade, mas na pluralidade que funda a própria linguagem" (2006, p. 143).

Com a sua poesia, Manoel de Barros leva ao entendimento de que os homens todos são filhos da mesma mãe natureza, e é por meio dessa natureza divinamente inspirada e instruída que o poeta convida todos a sentirem o Pantanal e o seu bestiário poético pelo qual ele se representa:

Natureza é fonte primordial?

- Três coisas importantes eu conheço: lugar apropriado para um homem ser folha; pássaro que se encontra em situação de água e lagarto verde que canta de noite na árvore vermelha. Natureza é uma força que inunda como os desertos. Que me enche de flores, calores, insetos, e me entorpece até a paradeza total dos reatores Então eu apodreço para a poesia. (BARROS, 1998, p. 38)

Diferente do humanismo tradicional, Manoel de Barros vê a natureza no centro da pessoa e não o indivíduo no centro do conhecimento da natureza. Nesse sentido, conhecer a realidade é um modo de se conhecer.

Em Arranjos para Assobio, Manoel de Barros brinca com definições do dicionário, invenções que se enquadram no todo de sua obra, reúne as suas imagens no que ele nomeia, substantiva, antropomorfiza e, por fim, vive, como é o caso da lesma:

Lesma, s.f.

Semente molhada de caracol que se arrasta / sobre as pedras, deixando um caminho de gosma escrito com o corpo Indivíduo que experimenta lascívia do ínfimo Aquele que viça de líquenes no jardim.

(BARROS, 1998, p. 44) 
A lesma consubstancia-se não pela distinção do asco, mas pela plenitude do seu viver. O seu arrastar a escrever na pedra um rastro iridescente revela o preternatural que aflora na própria natura (PRIOSTE, 2006, p. 156). E, nessa perspectiva, representa, em sua naturalidade rastejante, um avatar do telurismo (LINHARES, 2006, p. 89). A lesma então representa justamente isso, o contato dos seres com as coisas, simbolizando o próprio poeta que busca uma aderência à terra.

Já o termo "inseto" é descrito por Manoel de Barros nos moldes da sua singular modalidade do ver e do fazer estético como individuação de uma escória, concepção poética que, ao invés de produzir uma visão negativa, pessoaliza a individualidade da criatura com atributos humanos:

Inseto, s.m.

indivíduo com propensão a escória

Pessoa que se adquire da umidade

Barata pela qual alguém se vê

Quem habita os próprios desvãos

Aqueles a quem Deus gratificou com a sensualidade

(vide Dostoievski, Os irmãos Karamozov).

(BARROS, 1998, p. 45)

O poema, sob este princípio, há de se constituir como algo sem utilidade. "O poema é antes de tudo um inutensílio" (BARROS, 1998, p. 25). Desse modo, Barros parece refutar não apenas a utilidade das coisas, mas implantar uma crítica ao modo de pensar que se institui por polarizações, quando nesses pressupostos determina-se a um dos polos um valor incondicional. Daí, a diligência do poeta em atrever-se na via de um fazer que opera um outro vínculo entre saber e poder, ou seja, através do exercício livre da imaginação que conjectura objetos sem qualquer utilidade (PRIOSTE, 2006, p. 60). Nesse jogo poético, em que a linguagem é vital para o entendimento dos seres de seu bestiário, deve-se ressaltar que o sujeito lírico do poema desempenha experimentos linguísticos. 
Manoel de Barros expõe seus poemas se escrevendo, se reescrevendo e se inscrevendo na busca de uma linguagem que recupere a relação original do homem com a natureza. Conjuga assim, no mesmo espaço, o arcaico e as imagens remotas, com a reflexão em torno da poesia, que é a condição fundante da modernidade na literatura (CAMARGO, 1997, p. 240). Em determinado momento do seu bestiário poético, Manoel de Barros imita em tom de gozação o discurso moralizador e ironiza até mesmo as palavras da Bíblia Sagrada: "Nossa maçã é que come Eva” (Barros, 1998, p. 38). Ele posiciona-se do lado do diferente, talvez, por isso, predomine no curso da escrita o fluir do seu pensamento, a sintaxe do imaginário (RODRIGUES, 2006, p. 67).

Em "Exercícios adjetivos" a poesia de Manoel de Barros toca no que pode ser entendido como estética da substanciação, quando diz que não gosta de adjetivos e que os retira porque "eles enfraquecem as plantas" (BARROS, 2003a, p. 15), querendo com isso significar a função desgastada das qualidades convencionadas de má seiva nutridora. Assim, na poesia de Manoel de Barros, as palavras são agitadas e extraídas do seu lugar de conforto semântico tradicional e atiradas em inusitadas situações de significação, conforme pode-se notar no seguinte poema do bestiário do autor:

Manhã-passarinho

Uma casa terena de sol raiz no mato

Formiga preta minha estrela

Da asa parada pedras

Verdejantes voz

Pelada de peixe dia

De estar riachoso

Manhã-passarinho

Inclinada no rosto esticada

Até no lábio-lagartixa

Mosquito de hospício verruma

Para água arame de estender música

Sabão em zona erógena faca 
O bestiário poético de Manoel de Barros em Arranjos para assobio

\author{
Enterrada no tronco meu amor! \\ Esses barrancos ventados... \\ E o porco celestial. \\ (BARROS, 1998, p. 60)
}

Outro notável exercício adjetivo do bestiário poético de Manoel de Barros, que apresenta a transubstanciação ocorrida entre animais e coisas, pode ser exemplificado no caso dos caracóis e das paredes em "Os caramujos-flores":

\author{
Os caramujos-flores são um ramo de caramujos \\ que só saem de noite para passear \\ De preferência procuram paredes sujas, onde se \\ pregam e se pastam \\ Não sabemos ao certo, aliás, se pastam eles \\ essas paredes \\ Ou se são por elas pastados \\ Provavelmente se compensem. \\ (BARROS, 1998, p. 60)
}

Não se trata de um consumir o outro, mas de dividirem uma intimidade a ambos favorável. Todos estão em comunhão, sem hierarquia, os seres e o poeta. Este incorpora e vive o universo dos caramujos, das formigas, das aranhas. Como se vê, Manoel de Barros retoma em toda sua obra uma característica peculiar dos bestiários, qual seja, a ausência de interesse em classificarem os seus animais numa escala de importância ou de categorias que apreciasse o grau de evolução das espécies, desde os organismos mais ínfimos até os mais complexos.

No estado silencioso das lucubrações, cada coisa, cada animal, torna-se ser à sua maneira. A palavra rende-se, entrega-se ao poeta para que ele a verbalize na sua linguagem inicial. Manoel de Barros escreve poesia para externar essa inapetência pelo mundo dos homens, pois parece se sentir muito melhor entre as coisas 
O bestiário poético de Manoel de Barros em Arranjos para assobio Pedro Carlos Louzada Fonseca

imóveis e os bichos de seu bestiário do que entre os seres falantes (CASTELO, 1999, p. 112).

É comum o aspecto em Manoel de Barros de um sujeito lírico arcaico, que observa os animais, está em contato com a terra, para resgatar o homem já perdido (DAVID, 2005, p. 22). Porque o aprendizado do poeta, desde a sua infância, se dá pelo sensível, pela natureza. Assim, o poeta constrói seu bestiário como forma de escapar da ação do mundo. Afinal, o que Manoel de Barros deseja é estar em harmonia, deixando-se invadir pela natureza para viver plenamente. Essa atitude torna-se ainda mais evidente quando considera que é "preciso ser de outros reinos: o da água, o das pedras, o do sapo" (BARROS, 1990, p. 333). O projeto político e estético de Manoel de Barros realiza um tempo em que tudo pode vir a ser, um tempo que não tem marcas cronológicas, um tempo de absolutas realizações míticas, um tempo dos bichos-seres intemporais.

\section{Considerações finais}

Uma das grandes descobertas, ao se percorrer os poemas de Manoel de Barros, é o emprego da palavra como entidade capaz de manipular a realidade para recriá-la em um novo universo, o da poesia como propriedade demiúrgica. Essa não satisfação em simplesmente manusear a palavra poética como escrava de estéticas literárias canonizadas, conduz os seres e o mundo que compõem o seu bestiário poético, aspecto e tema propostos para análise neste artigo, ao caminho de uma absoluta liberdade enquanto seres-linguagem.

Dessa forma, os animais do bestiário poético pantaneiro de Manoel de Barros são tratados pelo poeta com considerável homologia relativamente ao seu modelo estético e ideológico, muitas vezes buscados à tradição do próprio bestiário medieval. Notável é a semelhança de atitude cosmovisiva do poeta com esse seu pro- 
O bestiário poético de Manoel de Barros em Arranjos para assobio Pedro Carlos Louzada Fonseca

tótipo medievo, ou seja, o seu respeito equânime a todos os animais que comparecem na sua poesia, desde os mais corriqueiros e aparentemente insignificantes pela sua vulgaridade até os mais enigmáticos e simbolicamente reveladores por sua prodigiosidade ou portentosidade (AUTOR, 2003, p. 169). Desde um simples inseto rastejante até uma grandiosa e altaneira ave, fazendo com que todos eles, ínfimos ou superiores, sejam avaliados como parte do sublime na natureza, considerada em todos os seus elementos cósmicos, seja o ar, com andorinhas, sabiás, pombas, borboletas; a terra, com formigas, onças, tartarugas, serpentes, lesmas, rãs, lagartos, vermes; e a água, com toda uma diversidade de peixes, todos fazendo parte do caleidoscópio vivo que forma o bestiário poético do autor.

\section{Referências}

BARROS, Manoel. Arranjos para assobio. 2. ed. Rio de Janeiro: Record, 1998.

BARROS, Manoel. Retrato do artista quando coisa. 3. ed. Rio de Janeiro: Record, 2002.

BARROS, Manoel. Ensaios fotográficos. 4. ed. Rio de Janeiro: Record, $2003 a$.

BARROS, Manoel. Livro de pré-coisas. 4. ed. Rio de Janeiro: Record, 2003b.

BARROS, Manoel. Tratado geral das grandezas do ínfimo. 3.ed. Rio de Janeiro, Record, 2005b.

BARROS, Manoel. Memórias Inventadas - A infância. São Paulo, Planeta, 2006a.

BOSI, Alfredo. Moderno e modernista na literatura brasileira. In BOSI, Alfredo. Céu, inferno. Ensaios de crítica literária e ideológica. São Paulo: Ática, 1987. 
O bestiário poético de Manoel de Barros em Arranjos para assobio Pedro Carlos Louzada Fonseca

CAMARGO, Goiandira de Fátima Ortiz de. A poética do fragmentário: Uma leitura da poesia de Manoel de Barros. 1997. Tese (Doutorado em Literatura). Faculdade de Letras, Universidade Federal do Rio de Janeiro, Rio de Janeiro.

CASTELO BRANCO, Lúcia (Org.). 7 olhares sobre os escritos de Barros e Pessoa v. 2. Faculdade de Letras da Universidade Federal de Minas Gerais, Belo Horizonte: Faculdade de Letras da Universidade Federal de Minas Gerais, 1995. Disponível em: http://www.letras.ufmg.br/site/publicacoes/download/7olhares2.pdf. Acesso em: 15 jan. 2008.

CASTELO, José. Inventário das Sombras. Rio de Janeiro: Record, 1999. DAVID, Nismária A. A (meta) poesia de Manoel de Barros: Do lúdico à manifestação do mito. 2004. Dissertação (Mestrado em Literatura). Instituto de Letras, Universidade Estadual de São Paulo.

FONSECA, Pedro Carlos Louzada. Animais e imaginário religioso medieval: Os bestiários e a visão da natureza. In: SANTOS, Dulce Oliveira Amarante dos; Maria Zaíra Turchi (orgs.). Encruzilhadas do imaginário: Ensaios de literatura e história. Goiânia: Cânone, 2003, p. 161-177.

FONSECA, Pedro Carlos Louzada. Bestiário medieval e discurso do gênero no descobrimento da América e na colonização do Brasil. Edusc, 2011.

GRÁCIA-RODRIGUES, Kelcilene. A inusitada semelhança entre as coisas na poesia de Manoel de Barros. São Paulo: Estudos Linguísticos, v. único, p. 1084-1089, 2006. Disponível em: http://gel.org.br/4publica-estudos-2006/sistema06/629.pdf. Acesso em: 17 dez. 2007.

GUIZZO, José Octávio. Sobreviver pela palavra. In: BARROS, Manoel.

Gramática Expositiva do Chão: Poesia quase toda. 2. ed. Rio de Janeiro: Civilização, 1992.

LACAN, Jacques. La lettre volée e L'instance de la lettre dans le signifiant. In: Écrits, Paris: Le Seuil, 1966.

LINHARES, Andrea Regina Fernandes. Memórias inventadas: Figurações do sujeito na escrita autobiográfica de Manoel de Barros. 2006.

Dissertação (Mestrado em História da Literatura). Faculdade de Letras, Fundação Universidade Federal do Rio Grande, Rio Grande. Disponível 
O bestiário poético de Manoel de Barros em Arranjos para assobio Pedro Carlos Louzada Fonseca

em: http://www.ppgletras.furg.br/disserta/andrealinhares.pdf. Acesso em: 20 dez. 2007.

PAZ, Octavio. O arco e a lira. Rio de Janeiro: Nova Fronteira, 1982. PRIOSTE, José Carlos Pinheiro. A unidade dual: (Manoel de Barros e a poesia). Rio de Janeiro, 2006. Tese (Doutorado em Ciência da Literatura). Faculdade de Letras, Universidade Federal do Rio de Janeiro, Rio de Janeiro. Disponível em: www.ciencialit.letras.ufrj.br/trabalhos/ jcprioste_unidade.pdf. Acesso em: 12 jan. 2007.

RODRIGUES, Ricardo Alexandre. A Poética da Desutilidade: Um passeio pela poesia de Manoel de Barros. 2006. Dissertação (Mestrado em Literatura). Faculdade de Letras, Universidade Federal do Rio de Janeiro, Rio de Janeiro, 2006. Disponível em: www.letras.ufrj.br/ciencialit/trabalhos/ricardoalexandre_poesia.pdf. Acesso em: 25 ago. 2007. TURIBA, Luiz João BORGES. Pedras aprendem silêncio nele. (entrevista). In: BARROS, Manoel de. Gramática expositiva do chão (poesia quase toda). $3^{\text {a }}$ ed. Rio de Janeiro, Civilização Brasileira, 1996.

VASCONCELOS, Vânia Maria de. A poética de Manoel de Barros- uma obra de invenção. Papéis, v. 7, n. 13, 2003.

WALDMAN, Berta. A poesia ao rés do chão. In: BARROS, Manoel de. Gramática Expositiva do chão - poesia quase toda. 2. ed. Rio de Janeiro: Civilização Brasileira, 1992.

\section{Agradecimentos}

À Goiandira de Fátima Ortiz de Camargo, por ter primeiro me revelado o belíssimo bestiário pantaneiro de Manoel de Barros. 